\title{
Responsabilidad patrimonial e indemnidad de los particulares. El nexo causal y el principio de solidaridad en la materia: el caso de la STS de 15 de julio de 1998
}

\author{
Francisco Javier Jiménez Lechuga
}

Sumario: I. GENERALIDADES. II. EL NEXO CAUSAL Y EL PRINCIPIO DE SOLIDARIDAD EN LA MATERIA. III. LA STS DE 15 DE JULIO DE 1998. IV. CONCLUSIONES. ADDENDA

\section{GENERALIDADES}

Quizá si alguien ha de pecar de reiterativo y machacón en punto al tratamiento del instituto resarcitorio en España la penitencia me debe a mí ser impuesta íntegramente ${ }^{1}$. Es lo cierto, empero, que no por ello me corresponde a mí el mérito de haberlo hecho mejor y con mayor acierto que otros ilustres colegas míos que están en mente de todos y, de manera especial, entre los administrativistas españoles ${ }^{2}$. Una y otra cosa están jus-

\footnotetext{
${ }^{1}$ F. J. JimÉnez LeChUga, La responsabilidad patrimonial de los poderes públicos en el Derecho español (una visión de conjunto), Ed. Marcial Pons, Madrid, 1999, y F. J. JiMÉNEZ LeCHUGA, «Responsabilidad patrimonial de las Administraciones Públicas. Indemnidad patrimonial de los perjudicados y equilibrio económico-financiero de las Corporaciones locales (el caso de la Sentencia del TSJA de 6 de febrero de 1995)», Revista de Estudios Locales (CUNAL), n. ${ }^{\circ} 10,1996$, pp. 61 y ss.

${ }^{2}$ E. García de Enterría y T. R. Fernández Rodríguez, Curso de Derecho Administrativo, Ed. Civitas, 2 vols., Madrid, 1998; L. Martín Rebollo, La responsabilidad patrimonial de la Administración en la jurisprudencia, Ed. Civitas, Madrid, 1977; F. GARRIDO FALLA, «La responsabilidad patrimonial del Estado Legislador», RAP, n. ${ }^{\circ} 118,1989$; J. Leguina VILLA, La responsabilidad patrimonial de la Administración pública, Ed. Tecnos, Madrid, 1983; M. Rebollo Puig, «Vía administrativa y jurisdicción competente para declarar la responsabilidad patrimonial de las Administraciones Públicas», Revista Jurídica de Andalucía, n. ${ }^{\circ}$ 26, 1998; J. R. PARADA VÁzquez, Derecho Administrativo, 3 vols., Ed. Marcial Pons, Madrid, 1999; L. Martín-Retortillo BAQuer, «Responsabilidad patrimonial de la Administración pública por lesión de los intereses legítimos», RAP, n. ${ }^{\circ} 42,1963$; L. Martín-Retortillo Baquer, Materiales para una Constitución, Ed. Akal, Madrid, 1983; A. Blasco EsteVE, «La relación de causalidad en materia de responsabilidad patrimonial de la Administración en la jurisprudencia reciente», REDA, n. ${ }^{\circ} 53,1987$; A. BLASCO EsTEVE, «La responsabilidad de la Administración por daños causados por actos administrativos», RAP, n. ${ }^{\circ} 91,1980$; A. Blasco EsteVE, La responsabilidad de la Administración por actos administrativos, Ed. Civitas, Madrid, 1983; R. Bocanegra SierRa, «La responsabilidad de concesionarios y contratistas de la Administración por daños causados a terceros», REDA,n. ${ }^{\circ} 18,1978$; M. F. CLAVERo ArÉVALo, La quiebra de la pretendida unidad jurisdiccional en materia de responsabilidad patrimonial de la Administración, Ed. Civitas, Madrid, 1992; M. ${ }^{a}$ C. Alonso GarCíA, La responsabilidad patrimonial del Estado legislador, Ed.
} 
tificadas, desde luego. En primer lugar, como pienso con M. HAURIOU ${ }^{3}$ que la Administración debe actuar, pero que debe hacerlo conforme a la ley (principio de legalidad) y que la Administración, en su actuación, si causa un daño a otro, debe repararlo íntegramente, se ve meridianamente que mi preocupación por el estudio del estado actual del desarrollo del instituto resarcitorio en España, con un Estado social y democrático de Derecho, como proclama el artículo 1.1 de la Constitución, deba ocuparme y preocuparme ${ }^{4}$ y ello sin compartir los alarmismos de cierto sector

Marcial Pons, Madrid, 1999; S. MuÑoz Machado, La responsabilidad civil concurrente de las Administraciones públicas, Ed. Civitas, Madrid, 1992; J. L. MARTínEZ-LóPEZ MuÑIz et alli, La responsabilidad patrimonial de las Administraciones Públicas, Ed. Marcial Pons, Madrid, 1999; F. J. DE Ahumada Ramos, La responsabilidad patrimonial de las Administraciones públicas, Ed. Aranzadi, Pamplona, 2000; R. GALÁN VIOQUE, «La indemnización de los daños y perjuicios producidos por una ley inconstitucional ¿Una rebelión del Tribunal Supremo frente al Tribunal Constitucional?», RAAP, n. ${ }^{\circ} 41,2001$; R. GALÁN VIOQUE, «De la teoría de la realidad de la responsabilidad del Estado legislador», RAP, n. ${ }^{\circ} 155,2001 ;$ J. C. LAGUNA DE PAZ, «Responsabilidad de la Administración por daños causados por el sujeto autorizado», $R A P, \mathrm{n} .^{\circ}$ 144, 2001; J. V. Morote SARRIÓN, «La responsabilidad solidaria de las Administraciones públicas en los procedimientos bifásicos», RAP, n. ${ }^{\circ} 154,2001$; A. Pérez Tenessa, «Sobre el diagnóstico prenatal como causa de responsabilidad», $R A P, \mathrm{n} .{ }^{\circ} 154$, 2001; J. Parada VÁzQuEz, «Justicia administrativa e irresponsabilidad de los servicios públicos», $R A P$, n. ${ }^{\circ} 153,2000$; L. PAREJo Alfonso, «El Estado social administrativo; algunas reflexiones sobre la "crisis" de las prestaciones y los servicios públicos», $R A P$, n. ${ }^{\circ} 153,2000$; J. MugA MuÑOZ, «El plazo para reclamar la responsabilidad de las Administraciones públicas. Una propuesta de política legislativa», RAP, n. ${ }^{\circ}$ 152, 2000; M. Cueto PÉrez, «Avances y retrocesos en la responsabilidad de las Administraciones Públicas tras la reforma de la Ley 30/1992», RAP, n. ${ }^{\circ} 152,2000$; A. SALERNo y R. MORENO FuENTES, «La responsabilidad de la Administración por daños que afectan a los "intereses legítimos" en el Derecho italiano. ¿Un cambio revolucionario?», RAP, n. ${ }^{\circ} 151,2000 ;$ J. A. SANTAMARÍA PASTOR, «La teoría de la responsabilidad del Estado legislador», RAP, n. ${ }^{\circ} 68,1972$; A. GALlego Anabitarte, Derecho general de organización, IEAL, Madrid, 1971; J. Pérez Martos, «Sobre la responsabilidad del Estado por incumplimiento del Derecho comunitario», Actualidad Administrativa, n. ${ }^{\circ}$ 26, 1997; F. J. JimÉNEZ LeChUGA, «La leyes singulares en el Derecho español: de nuevo sobre el caso Rumasa y su epílogo la S.T.E.D.H. de 23 de junio de 1993»; en Revista Cortes Generales n. ${ }^{0}$ 37/1996; M. ${ }^{a}$ BeladíEz Rojo, Responsabilidad e imputación de daños por el funcionamiento de los servicios públicos, Tecnos, Madrid, 1997; F. González NAvarro, «Responsabilidad de la Administración por daños a terceros por el empresario de un servicio público», $R D A F, \mathrm{n} .^{\text {os }} 44-45,1976$; M. Rebollo Puig, «Servicios públicos concedidos y responsabilidad de la Administración: imputación o responsabilidad por hecho de otro. Comentario a la STS de 9 de mayo de $1989 », P J$, n. $^{\circ} 20$, 1990; A. JIMÉNEZ BLANCO, «Responsabilidad administrativa por culpa in vigilando o in ommittendo», PJ, n. ${ }^{\circ}$ 2, 1986; Rivero Ortega, El Estado vigilante, Ed. Tecnos, Madrid, 2000; A. Nieto García, «La relación de causalidad en la responsabilidad del Estado», REDA, n. ${ }^{\circ} 4,1975$; A. NiETo GARCía, «La relación de causalidad en la responsabilidad administrativa: doctrina jurisprudencial», REDA, n. ${ }^{\circ}$ 51, 1986; J. GonZÁlez Pérez, Responsabilidad patrimonial de las Administraciones públicas, Ed. Civitas, Madrid, 1995; J. R. FERNÁNDEZ TORRES, Jurisdicción administrativa revisora y tutela judicial efectiva, Ed. Civitas, Madrid, 1998; O. Mir PuigPelat, La responsabilidad patrimonial de la Administración sanitaria. Organización, imputación y causalidad, Ed. Civitas, Madrid, 2000 y L. Cosculluela Montaner, Manual de Derecho Administrativo, Ed. Civitas, Madrid, 1992.

${ }^{3}$ M. Hauriou, Précis de Droit Administratif, Paris, 1921.

${ }^{4}$ Como expuse en mi comentario al libro de F. J. DE Ahumada Ramos, «La responsabilidad patrimonial de las Administraciones Públicas», Ed. Aranzadi, Pamplona, 2000, en Revista de Estudios Locales (CUNAL), n. ${ }^{\circ}$ 44, 2001. 
doctrinal que ve la institución como una plasmación del principio de solidaridad social y, en consecuencia, como un potencial grave riesgo para las arcas públicas ${ }^{5}$. En segundo lugar, como es bien conocido, el propio GARCÍA DE ENTERRÍA ya tempranamente se ocupó de todos estos asuntos con el estudio detenido de la Ley de Expropiación Forzosa, de 16 de diciembre de $1954^{6}$, a la que luego siguieron la Ley de Régimen Jurídico de la Administración del Estado, de 26 de julio de 1957, la Ley reguladora de la Jurisdicción Contencioso-Administrativa, de 27 de diciembre de 1956, la Ley de Procedimiento Administrativo, de 17 de julio de 1958, y la no menos importante - esto no ha sido suficientemente destacado por nuestra doctrina pero tiene sus precedentes en el Derecho alemán- Ley de Régimen Local, de 24 de junio de 1955 (hoy derogada).

Es evidente que en épocas anteriores sólo parcialmente se regulaba la institución aunque la total irresponsabilidad que del Estado se predicaba por la doctrina con anterioridad a la promulgación de la legislación anteriormente citada no es aceptable en términos generales, como ha puesto de relieve recientemente el profesor A. GALLEGO ANABITARTE ${ }^{7}$, porque existen vestigios tanto en nuestro Derecho como jurisprudencia decimonónicos de esto que afirmo y que señala atinadamente el profesor de la Universidad Autónoma de Madrid ya citado. Sin embargo - como no podía ser de otro modo-, no interesa aquí tanto el proceso «holístico» cuanto el estado que presenta el instituto jurídico objeto de este trabajo en los albores del siglo XXI y a lo que voy a dedicar brevemente mis esfuerzos antes de entrar de lleno en el comentario de la decisión judicial que era un compromiso que ya tenía yo contraído con los lectores hace algunos años ${ }^{8}$.

Resulta, pues, que - sin entrar en mayores abundamientos en este lugar- el instituto resarcitorio se encuentra regulado en el artículo 106.2 CE, los artículos 139 a 145 de la Ley 30/1992, de 26 de noviembre, de Régimen Jurídico de las Administraciones Públicas y del Procedimiento Administrativo Común, el artículo 54 de la Ley 7/1985, de 2 de abril, reguladora de las Bases del Régimen Local, el Real Decreto 429/1993, de

\footnotetext{
5 J. A. Santamaría Pastor y L. Parejo Alfonso, Derecho Administrativo, CERA, Madrid, 1989.

${ }^{6}$ E. García de Enterría, Los principios de la nueva Ley de Expropiación Forzosa, Ed. Civitas, Madrid, 1984.

7 A. Gallego Anabitarte, Derecho Administrativo, 2 vols. Ed. Marcial Pons, Madrid, 2000/2001.

${ }^{8}$ F. J. JimÉNEz LeChUGA, «Responsabilidad patrimonial de las Administraciones públicas. Indemnidad patrimonial de los perjudicados y equilibrio económico-financiero de las Corporaciones locales afectadas (el caso de la sentencia del TSJA, Sala de lo Contencioso-Administrativo de Granada, Sección primera, de 6 de febrero de 1995)», Revista de Estudios Locales (CUNAL), n. ${ }^{\circ}$ 10, 1996.
} 
26 de marzo, por el que se regulan los procedimientos a seguir en materia de responsabilidad administrativa, y las referencias que, en algunos casos, se hace a la institución en los distintos Estatutos de Autonomía ${ }^{9}$. El sistema de responsabilidad administrativa en España se ha definido como objetivo, independiente, sistemático autónomo respondiendo así a su configuración constitucional ${ }^{10}$. Precisamente describiendo la situación actual, ha escrito algún colega mío del que discrepo en cuanto al alarmismo manifestado respecto de la institución en algunos lugares ${ }^{11}$ que el pacífico estado de cosas en relación con la concepción del instituto resarcitorio ha venido a removerse con la irrupción de dos líneas doctrinales:

a) La primera de ellas, partiendo de una aceptación global del modelo, ha comenzado a detectar en el mismo deficiencias alarmantes: el régimen de imputabilidad de responsabilidad se halla construido con un cortísimo haz de conceptos (los resumidos en los dos primeros apartados del art. 139 de la Ley 30/1992) que permiten construir razonamientos teóricos (mejor retóricos) en orden a la resolución de reclamaciones concretas, pero que en sí mismos no parecen fácilmente susceptibles de objetivación; su indeterminación y flexibilidad, la admisión de salvedades a los mismos (así, la indemnizabilidad de los daños morales, en contraste con el requisito de la evaluabilidad económica del daño), así como la multiplicidad de técnicas para su determinación concreta (por todas, la panoplia de teorías acerca de la relación de causalidad) son circunstancias reveladoras de que el sistema reposa sobre un presupuesto teórico, no siempre explicitado con la debida claridad; el de que la imposición del deber de indemnizar constituye una pura manifestación del más puro decisionismo judicial caso a caso, al que las construcciones teóricas prestan un argumento polivalente, capaz de justificar fallos de sentido perfectamente opuesto, pero no asideros dogmáticos, puntos de referencia objetivos para aquellos jueces que no gustan de la mera tarea de justificar decisiones intuitivas. Partiendo de la aceptación del modelo y de la constatación de sus deficiencias, esta línea doctrinal se ha propuesto la meritoria tarea de profundizar en los conceptos tradicionales, intentando conferirles perfiles cada vez más afinados al objeto de elevar su nivel de objetividad ${ }^{12}$.

\footnotetext{
9 Ley Orgánica 6/1981, de 30 de diciembre, por la que se aprueba el Estatuto de Autonomía para Andalucía.

10 F. J. Jiménez Lechuga, La responsabilidad patrimonial de los poderes públicos en el Derecho español (una visión de conjunto), Ed. Marcial Pons, Madrid, 1999.

11 J. A. Santamaría Pastor, en el «Prólogo» al libro de F. J. De Ahumada Ramos, op. cit., pp. 18 y ss.

12 J. A. Santamaría Pastor, op. cit. (prólogo).
} 
b) La segunda línea doctrinal es de mucho más alcance y profundidad, en cuanto viene a poner en cuestión globalmente el sistema vigente. Lo que se discute en ella es la validez de conjunto del modelo recibido, al que se considera, de una parte, insusceptible de un grado de objetivación aceptable y, sobre todo, inviable en términos financieros. Un régimen de responsabilidad objetiva pura, basado en el concepto de daños causados por el desarrollo normal o anormal de la actividad administrativa, se sostiene en la medida en que el número y el volumen de las reclamaciones sea muy limitado, como hasta ahora ha ocurrido; pero una ampliación sustancial del número de reclamaciones y de las sentencias estimatorias de las mismas resultará inasumible por cualquier Hacienda pública por saneados que sean sus estados contables. Que esta advertencia no constituye puro catastrofismo lo acreditan las críticas experiencias actuales de algunos países latinoamericanos, que importaron el diseño objetivo de la responsabilidad administrativa extracontractual sin disponer de una judicatura tan sensible como la española hacia los intereses públicos y la estabilidad de sus finanzas públicas ${ }^{13}$.

Ni que decir tiene que no participo yo de las opiniones del apartado b) que sustenta abiertamente el profesor J. A. SANTAMARÍA PASTOR, tesis de las que se muestra abiertamente partidario más adelante —en el prólogo al libro de F. J. DE AHUMADA RAMOS- y mis razones las expuse, aunque muy parcialmente, en el propio comentario al libro de F. J. DE AHUMADA RAMOS ${ }^{14}$. Razón ésta por la que no abundaré aquí ahora pero que, repito, no comparto ese alarmismo del profesor J. A. SANTAMARÍA PASTOR y sí las tesis mayoritarias. Estoy especialmente de acuerdo con la postura que mantiene J. LEGUINA VILLA como ya dije hace dos años en otro lugar ${ }^{15}$. Hay que reconocer, de todas formas, que, aunque la doctrina mayoritariamente sostiene el carácter de la responsabilidad administrativa como objetiva y directa, no es ésta una exigencia constitucional y, en consecuencia, salvo que la competencia es exclusiva del Estado en cuanto a la configuración de un régimen unitario, nada impediría la vuelta a la utilización del elemento culpabilístico, al menos desde un punto de vista de legalidad ordinaria si, por ejemplo, el Derecho comunitario europeo así lo exigiese. Esto sería, en cambio, un serio retroceso. También el profesor F. PANTALEÓN PRIETO se muestra partidario de una reforma en profundi-

\footnotetext{
13 J. A. Santamaría Pastor, op. cit. (prólogo).

14 Mi comentario en Revista de Estudios Locales (CUNAL), n. ${ }^{\circ}$ 44, 2001.

15 F. J. Jiménez Lechuga, La responsabilidad patrimonial de los poderes públicos en el Derecho español (una visión de conjunto), Ed. Marcial Pons, Madrid, 1999.
} 
dad del sistema y se lo he oído decir en Granada y leído en algún otro lugar conocido ${ }^{16}$.

La posición que mantiene mi amigo F. GARRIDO FALLA puede considerarse intermedia y así lo ha puesto de relieve en su Tratado al que ahora remito. Recientemente ha escrito que, afortunadamente, de unos años a esta parte se están produciendo reacciones que tienden a afirmar una expansiva jurisprudencia cuyas últimas consecuencias aún están por ver. J. R. PARADA VÁZQUEZ - afirma F. GARRIDO FALLA al que ahora sigo y con el que coincido parcialmente en su concepción del instituto resarcitorio- se ha referido a cómo la generosidad de la fórmula legal española ha producido un cierto pánico doctrinal — que PARADA VÁzQUEZ no comparte, por cierto - del que son exponente NIETO GARCÍA y SÁNCHEZ MORÓN, advirtiendo que en una sociedad que tiene por base el beneficio individual y que, por consiguiente, dista de alcanzar el ideal igualitario, la antedicha socialización de los riesgos podría conllevar a resultados excesivos a través de una hipertrofia del sistema de responsabilidad civil, cargando a las espaldas de la sociedad en su conjunto con pesados gastos que, en justicia, tampoco ella debe soportar ${ }^{17}$.

Me referiré, por último, para concluir este apartado, a unas opiniones de R. GALÁN VIOQUE — en realidad lo que recoge son las opiniones de J. LEGUINA VILLA con las que estoy en sintonía según es sabido y para la responsabilidad del Estado legislador-que en un reciente trabajo que constituye, como él mismo afirma, una síntesis de su tesis doctoral $-\mathrm{y}$ que, por cierto, tiene la gentileza de citarme, lo que todavía no ha hecho un profesor leonés que creo buen amigo - 18 conviene traer aquí a colación unas afirmaciones según las cuales, la naturaleza abstracta de los preceptos legales - refiriéndose, como he dicho, a la responsabilidad por leyes y su aplicación-y su alcance general han sido también invocados como argumentos por quienes se oponen a la responsabilidad legislativa. Para J. Leguina ViLLA, unas medidas legales «aun cuando sean más restrictivas o limitativas que las anteriormente vigentes, no establecen privilegios singulares o beneficios (sacrificios) especiales en la esfera jurídico patrimonial de personas individualmente consideradas, ni pueden causar lesiones antijurídicas o quebrantos patrimoniales que no se tenga el deber

\footnotetext{
${ }^{16}$ F. Pantaleón Prieto, «Los anteojos del civilista», DA, n. ${ }^{0 s} 237-238,1994$.

17 J. L. MartíneZ-LóPeZ MuÑIz et alli, La responsabilidad patrimonial de los poderes públicos, Ed. Marcial Pons, Madrid, 1999, pp. 34 y ss.

${ }^{18}$ R. Galán Vioque, «De la teoría de la realidad de la responsabilidad del Estado legislador», $R A P$, n. ${ }^{\circ} 155,2001$, pp. 285 y ss.
} 
jurídico de soportar, sino que - y ello es consustancial a toda intervención legal de configuración de los derechos - tienen por objeto la regulación en abstracto del nuevo contenido del derecho subjetivo, afectan por igual a la generalidad de sus potenciales destinatarios a sujetarse el nuevo régimen legal» ${ }^{19}$. Esta afirmación — siempre según R. GALÁN VIOQUE, que no comparto, y sí la de J. LEGUINA VILLA- desconoce la existencia de leyes singulares y leyes medida ${ }^{20}$, cuya validez ha sido confirmada por nuestro Tribunal Constitucional ${ }^{21}$ sino que confunde los dos planos en los que pueden verse las normas jurídicas ${ }^{22}$. Desde el punto de vista del Derecho objetivo, las leyes se limitan a concretar el ámbito de libertad propio de las personas creando un universo de reglas jurídicas. Parece claro que en este plano no se puede hablar de lesiones patrimoniales que sean imputables a las leyes. Pero junto a esta perspectiva horizontal de las normas legales, que se plasma en su fría publicación en los boletines oficiales como exigencia derivada del principio de seguridad jurídica, aparece una segunda dimensión, la del modo en que su entrada en vigor alcanza a las situaciones subjetivas ya preexistentes y argumenta también nuestro autor que, según estas ideas, el Consejo de Estado francés dictó el famoso arrêt La Fleurette, de 14 de enero de 1938, otorgándose una indemnización en concepto de responsabilidad patrimonial a la única empresa que había tenido que cesar en su actividad como consecuencia de la prohibición general de comercializar productos sucedáneos de la leche establecida por una ley francesa de protección del sector lácteo, no habiendo sido sensible nuestro Tribunal Supremo a estas tesis por los actos legislativos que sólo con la sentencia de 30 de noviembre de 1992 - que ya comentó en su momento F. GARRIDO FALLA - tuvo ciertos visos de hacerse realidad aunque la situación para mí no es todavía clara pese a la opinión mayoritaria como la representada entre otros, por S. GONZÁLEZ-VARAS IBÁÑEZ y en lo que no entraré por el momento ${ }^{23}$.

Sin embargo, la situación, en líneas generales, es la que he descrito y son pocas las discrepancias, excepto los falsos alarmismos a los que tam-

\footnotetext{
19 J. Leguina Villa y M. SÁnchez Morón, La nueva Ley de Régimen Jurídico de las Administraciones Públicas y del Procedimiento Administrativo Común, Ed. Tecnos, Madrid, 1993.

${ }^{20}$ F. J. JimÉnez LeChUGA, «Las leyes singulares en el Derecho español: de nuevo sobre el caso Rumasa y su epílogo, la STEDH de 23 de junio de 1993», Revista de las Cortes Generales, n. ${ }^{0}$ 37/1, 1996.

${ }^{21}$ STC 166/1986, de 19 de diciembre.

${ }^{22}$ E. García de Enterría, Los principios de la nueva Ley de Expropiación Forzosa, Ed. Civitas, Madrid, 1984.

${ }^{23}$ Así lo manifestó éste en su comentario a mi libro sobre la materia en la Revista de Estudios Locales (CUNAL), n. ${ }^{\circ} 42,2000$ y en algún trabajo publicado en la REDA, sobre el particular (1999).
} 
bién ya me he referido anteriormente. Voy ahora sobre la siguiente cuestión atinente a nuestro objeto de estudio y que servirá para comprender mi posición sobre la materia.

\section{EL NEXO CAUSAL Y EL PRINCIPIO DE SOLIDARIDAD EN LA MATERIA}

Parece conveniente, a los efectos de la exposición de la sentencia del Tribunal Supremo que seguidamente se hará, detenerse siquiera sea brevemente en estos dos aspectos — podríamos decir que elementos constitutivos del instituto resarcitorio - trascendentales para declarar la responsabilidad patrimonial de una Administración pública y sobre los que la resolución judicial objeto de comentario hace hincapié de forma breve e incidental pero con base en toda la doctrina jurisprudencial anterior, tanto por el Tribunal a quo como por el propio Tribunal Supremo. En efecto, y como ha afirmado recientemente algún estudioso de estos asuntos, en términos generales, a la producción de cualquier daño, empíricamente considerado, habrán podido concurrir un número indefinido de agentes incluyendo a la víctima y a las fuerzas de la naturaleza. Pero desde un planteamiento jurídico, también teórico, esta constatación no es determinante a efectos de imputar o excluir la responsabilidad patrimonial respecto de ningún sujeto. Lo que verdaderamente importa, en todo caso, es determinar si mediante un comportamiento activo u omisivo se ha causado por la Administración la lesión del derecho o interés jurídicamente protegido que se invoca. En consecuencia, el nexo causal no hay que trabarlo tanto entre una acción material y el daño de un bien (aunque en los supuestos en que se imputa una responsabilidad por un comportamiento activo dicho vínculo material deba estar siempre presente), sino, principalmente, entre un comportamiento personal y un derecho - del que su titular se dice privado-, contemplada la relación normativamente, esto es, sobre la base de la concreta posición que respecto del derecho en cuestión tienen el titular y el agente o agentes que concurren a su privación, lo que vendrá determinado por el título constitutivo del derecho y el ordenamiento jurídico ${ }^{24}$. En este sentido es interesante la STS de 18 de enero de 1982, Ar. 346 aunque no es, desde luego, la primera en la materia ${ }^{25}$.

\footnotetext{
${ }^{24}$ F. J. De Ahumada Ramos, La responsabilidad patrimonial de las Administraciones públicas, Ed. Aranzadi, Pamplona, 2000.

${ }^{25}$ La STS de 18 de enero de 1982, Ar. 346, dice lo siguiente:
}

«... la acción de la Administración pública debe estar siempre regida por criterios de congruencia, oportunidad y proporcionalidad de tal forma que sus poderes sean utilizados en la 
Por tanto - en opinión de cierto sector doctrinal cuya opinión suscribo enteramente-, la jurisprudencia española ha venido exigiendo tradicionalmente una relación no sólo directa, sino exclusiva, entre la actuación de la Administración y la lesión, aunque se percibe cada vez más una postura aperturista al respecto, tanto en la doctrina del Consejo de Estado como entre la jurisprudencia ${ }^{26}$, especialmente la del orden civil (competente, junto con el contencioso-administrativo, hasta la vigencia de la Ley 30/1992, que impuso la unidad de fuero - contencioso-administrativa-), parece obvio que la falta de la propia víctima del hecho o de un tercero no son capaces por sí mismas de eliminar en su totalidad la influencia que en la producción del daño final haya podido tener la actuación de la Administración ${ }^{27}$. En estos casos de intervención de terceros en la producción del daño la solución que se puede valorar como más correcta, a la que apunta nuestra doctrina más autorizada (pero que no prevé la Reco-

medida y dentro de los límites que correspondan con los fines en atención a los cuales son legalmente concedidos, adquiriendo dichos criterios una exigencia más intensa cuanto más excepcionales y portadores de riesgos sean los medios otorgados como ocurre en el caso de los funcionarios de policía a los cuales, por su preparación específica y por estar dotados de armas de fuego capaces de producir graves e irreversibles daños a la vida humana, les es exigible que su actuación les venga presidida de una apreciación serena de las circunstancias que concurren en las condiciones con que se enfrentan y empleen sus armas de fuego solamente en aquellos casos en que dichas circunstancias hagan razonable prevenir una situación de riesgo o peligro real para ellos, o terceras personas, únicamente superable mediante esa utilización, y lo hagan en la forma adecuada para evitar consecuencias irreparables que no vengan justificadas por la gravedad del contexto de hecho en que se encuentran, pues en otro caso su acción resultará desproporcionada con la importancia y naturaleza de la conducta ilícita que tratan de reprimir, si a consecuencia del uso de sus armas ocasionan al responsable de ella un daño que excede de aquel que normalmente debe sufrir por el hecho de la puesta en movimiento de las fuerzas de policía, que en el supuesto de autos era su detención y entrega a la autoridad judicial y en el que la reacción policial fue claramente desproporcionada a la situación creada por la víctima en cuanto que es a todas luces desproporcionado producir por disparos de arma de fuego la muerte de una persona que se limita a huir de la policía sin haber dado muestra alguna de agresividad o resistencia, sin que el contexto general de dicha situación permitiera racionalmente suponer la creación de un peligro real e inminente para la fuerza pública, que había sido convenientemente distribuida, o para terceras personas y en su consecuencia procede rechazar el fundamento denegatorio de los acuerdos recurridos por no concurrir proporcionalidad entre la conducta de la víctima y el daño sufrido por el funcionamiento del servicio público fundamento que en definitiva se apoya, en el caso aquí contemplado, en la inadmisible convicción de que la simple y pura huida de una persona desatendiendo las órdenes de "alto a la policía" autoriza sin más a ésta para utilizar sus armas de fuego con resultado mortal para el que huye, olvidando que la vida humana es el supremo bien de nuestra cultura y ordenamiento jurídico, según consagra el artículo 15 de nuestra Constitución, que ninguna persona o autoridad puede destruir salvo los supuestos excepcionales legalmente previstos, entre los cuales desde luego no puede influirse el de autos».

${ }^{26}$ L. Martín Rebollo, «La responsabilidad patrimonial de las Administraciones públicas en España: estado de la cuestión, balance general y reflexión crítica», $D A, n{ }^{\text {os }} 237-238,1994$.

27 E. García de Enterría y T. R. Fernández Rodríguez, Curso de Derecho Administrativo, 2 vols., Ed. Civitas, Madrid, 2000. 
mendación) ${ }^{28}$, sería, más que la disminución o desaparición de la responsabilidad administrativa, la atribución de responsabilidad solidaria a todos los coautores, de forma que el particular lesionado no sufra los perjuicios de la intervención de terceros) ${ }^{29}$. Por otra parte, la participación de terceras personas en la producción del daño puede dar lugar - en España- a problemas de competencia entre diversos órdenes judiciales que, como tales, la citada Recomendación no tiene en cuenta ${ }^{30}$.

Interesa ahora decir algo sobre la aplicación al instituto resarcitorio de las tesis procesales de las acciones solidarias o, dicho más sencillamente, de la responsabilidad solidaria de las Administraciones públicas, tanto en los procedimientos administrativos bifásicos como en los polifásicos. Yo ya mantenía esta posición desde comienzos de 1990 y así vino a confirmarlo la promulgación de la Ley 30/1992, de 26 de noviembre (modificada por la Ley 4/1999, de 13 de enero). Y encuentro - no sin cierto regocijo, desde luego - que ahora algún autor ha estudiado este asunto más detenidamente ${ }^{31}$ ) acogiendo en parte mis planteamientos. Me refiero a R. GALÁN VIOQUE quien afirma que - tratando el asunto de la responsabilidad patrimonial del Estado legislador - la STS de 30 de noviembre de 1992 tiene una decidida importancia en este camino o lucha contra las inmunidades del poder, lo que no es nuevo, pues este hecho fue puesto de relieve en su momento por F. GARRIDO FALLA y, en otro lugar, que el papel del Tribunal Constitucional es fundamental en la configuración de la responsabilidad del Estado por la promulgación y aplicación de sus leyes. Pero, en realidad, quien se refiere más exactamente al asunto que ahora me ocupa es J. V. MOROTE SARRIÓN que es quien verdaderamente se refiere a mis tesis y a las de otros profesores sobre la materia ${ }^{32}$.

Afirma éste que, tras la modificación introducida por la Ley 4/1999, de 13 de enero, el legislador se hace eco de las críticas que había recibido la anterior relación del artículo y sustituye la expresión «fórmulas colegia-

\footnotetext{
${ }^{28}$ Se refiere a la Recomendación del Comité de Ministros del Consejo de Europa. Hay que decir, por cierto, que, en mi opinión la aplicación del Derecho comunitario europeo en la materia (en general) sería regresivo para el ordenamiento jurídico español al ser más avanzado este instituto en España que en los demás países europeos (al menos desde el punto de vista técnico y doctrinal).

29 E. García de Enterría, op. cit.

30 J. L. MarTínez-LóPez MuÑIz et alli, La responsabilidad patrimonial de los poderes públicos, Ed. Marcial Pons, Madrid, 1999, pp. 72 y ss.

${ }^{31}$ R. Galván Vioque, «De la teoría de la realidad del Estado legislador», RAP, n. ${ }^{\circ}$ 155, 2001.

32 J. V. Morote Sarrión, «La responsabilidad solidaria de las Administraciones públicas en los procedimientos bifásicos», RAP, n. ${ }^{\circ} 154,2001$.
} 
das de actuación» por la de «fórmulas conjuntas de actuación». Se decanta por extender la solidaridad a todos aquellos supuestos en que existe participación coordinada en la producción del daño. Con relación a los procedimientos bifásicos, tras la reforma, quedan incluidos en el artículo $140.1 \mathrm{y}$, por tanto, la regla general seguirá siendo la solidaridad. Es un supuesto de actuación conjunta ya que una disposición de carácter normativo o un instrumento acordado divide un procedimiento en dos fases, cada una de las cuales se asigna a un ente diferente. Se trata de un supuesto de participación sucesiva de dos o más entes en la prestación de un servicio o en el desempeño de una actividad, y no de un supuesto en que dos Administraciones actúan de forma independiente y, ocasionalmente, concurren a la producción de un daño.

Esto que afirma J. V. MOROTE SARRIÓN me parece tanto más acertado, cuanto que existe un óbice procesal ante la imposibilidad de aplicación del litisconsorcio pasivo necesario, ya que la nueva Ley (la Ley 29/1998, de 12 de julio) no lo ha regulado así en este caso y sustancialmente, como pone de relieve este autor, sigue manteniendo su carácter objetivista y, por lo tanto, su objeto son los actos administrativos, y no los derechos subjetivos de los litigantes ${ }^{33}$.

Debe tenerse en cuenta, por lo demás, que, aunque el citado autor se refiere a la responsabilidad solidaria de las Administraciones públicas en los procedimiento bifásicos, estas tesis pueden defenderse y extenderse o generalizarse. Además, y contrariamente a lo que piensa algún sector doctrinal $-\mathrm{y}$ la sentencia que será objeto de este comentario jurisprudencial lo pone claramente de manifiesto, a pesar de que los hechos se produjeron con anterioridad a la Ley 30/1992, de 26 de noviembre- no es la titularidad del servicio uno de los elementos - sólo el único junto con los demás que establece la ley_- para servir de título de imputación de la responsabilidad a una Administración pública. Antes al contrario, y, lege data, puede afirmarse la solidaridad cuando — como en el caso que seguidamente analizaré pero a la luz de la nueva Ley- el servicio público haya funcionado mal o dejado de funcionar cuando, en su creación hayan intervenido varias Administraciones públicas, con independencia de cuál sea el sujeto titular del meritado servicio público y el perjudicado podrá

\footnotetext{
33 Ésta es también mi opinión. El contencioso español es todavía deudor del Derecho administrativo francés. En contra se manifiestan S. GonZÁLEZ-Varas IBÁÑEZ con quien discrepo. También GARCÍA DE ENTERRÍA en su intervención con ocasión de la celebración del II centenario de la creación del Consejo de Estado francés parece decantarse por el subjetivismo y, en consecuencia, por el modelo alemán. Yo discrepo modestamente del parecer del profesor leonés y de mi amigo García DE ENTERRÍA en este aspecto relativo al carácter subjetivista de la Ley 29/1998, de 23 de julio.
} 
dirigirse contra cualquiera de los Entes públicos intervinientes y, en su caso, los Tribunales repartir la carga de la indemnización debida proporcionalmente. Cabe incluso la repetición por un Ente público condenado al pago total frente a quienes hayan colaborado con él en la creación del servicio si, finalmente, se ha producido un daño individualizado y económicamente evaluable imputable a la Administración. Estas tesis no serán seguramente compartidas por algunos pero, a la vista del caso presente, $\mathrm{y}$ con el Derecho positivo vigente, parece lo más razonable. En otra ocasión estudiaré todo esto con más detenimiento.

Precisamente advierte J. V. Morote SARRIÓn que la aplicación del principio de solidaridad no implica la búsqueda de un único patrimonio, que la solidaridad que ha establecido el legislador en la materia es coherente con la institución de la responsabilidad administrativa, como un sistema de garantía social — solución ésta que comparto enteramente- y porque se gana en seguridad jurídica al introducir una cláusula clara que hace innecesario acudir a la interpretación extensiva de la jurisprudencia a la vez que permite al operador jurídico elegir con seguridad a la parte demandada ${ }^{34}$.

También parecen congruentes, en mi opinión, sus afirmaciones conforme a las cuales la opción de la solidaridad es conforme con el sistema general de responsabilidad establecido en la Ley 30/1992, porque nuestro sistema es de responsabilidad directa, por lo que no es necesario proceder contra el agente público causante de la lesión, sino que se procede directamente contra la Administración y, si ésta se ve obligada a resarcir el daño causado, después deberá usar la acción de regreso contra el agente ${ }^{35}$, aunque éste sea fácil o difícilmente identificable. Hay una concurrencia de causación del daño, aunque desproporcionada, ya que, como apunta M. ${ }^{a}$ BeladíEz Rojo, mientras que uno de los sujetos (el funcionario, el agente) ha sido el que ha causado el daño - dado además que le resulta imputable por haber sido él quien ha creado el riesgo que se ha materializado en el resultado lesivo-, el otro (el empresario, la Administración) no ha tenido otra participación en el daño que la de crear con su organización el riesgo de que sus agentes causen daños a terceras personas ${ }^{36}$. Además, se trata de un problema de justicia material y sobre todo procesal.

\footnotetext{
${ }^{34}$ STS de 15 noviembre de 1993, Ar. 10115.

35 Ésta es otra de las novedades de la reforma de 1999 que establece la obligación de ejercitar la acción de regreso para que pague el funcionario causante del daño. En realidad, las acciones de regreso contra el funcionario están inéditas en nuestro Derecho en este terreno.

${ }^{36}$ M. ${ }^{a}$ Beladízz Rojo, Responsabilidad e imputación de daños por el funcionamiento de los servicios públicos, Madrid, 1997.
} 
También S. MuÑOZ MACHADO se ha ocupado ya hace algunos años de este asunto y afirma que existen líneas jurisprudenciales favorables a declarar la responsabilidad de una Administración pública en los supuestos de concurrencia con un particular (un concesionario o una persona que ejerce una actividad reglamentada) que, aunque se exceden, según se sabe, al imputar el daño a la Administración de modo director, reflejan una preocupación que debe compartirse ${ }^{37}$. La responsabilidad es, en efecto, una institución de garantía de los bienes y derechos de quienes resultan lesionados por la actividad de otros. La garantía es mayor en la medida en que la indemnización se asegura. Y la jurisprudencia, sin demasiada razón jurídica algunas veces, ha encontrado en el presupuesto público el asegurador más a la mano de los desfallecimientos de los patrimonios privados de los daños causados. Ya advertía S. MUÑOZ MACHADO en 1992 que, aunque debe hacerse mediante ley, no había problema alguno en reconocer la coparticipación de las Administraciones públicas en la causación del daño conforme al artículo 1.137 del Código civil por los propios Tribunales, añadiendo que, en el resto de los supuestos de concurrencia, hay que declarar la responsabilidad directa y solidaria de las Administraciones públicas intervinientes en la producción del daño. Con la única excepción de que, aunque se haya coparticipado en la lesión, la medida de la participación de cada interviniente en la producción del daño puede cuantificarse económicamente de modo exacto. En tal caso, aunque la responsabilidad sea múltiple - sostiene S. MUÑOZ MACHADO y yo mismo-, la deuda es parciaria y debe exigirse separadamente a cada partícipe. La plus garantía de la solidaridad debe reservarse para los casos en que es difícil o imposible evaluar de modo previo a la acción la cuantía de la deuda exigible a cada uno de ellos.

Finalmente - como advierte J. L. DE LA VALLINA VELARDE-, hay que indicar que la regulación general y uniforme del sistema de responsabilidad para todas las Administraciones públicas no es algo novedoso en nuestro ordenamiento jurídico, ya que tuvo su implantación preconstitucional con la Ley de Expropiación Forzosa de 1954. Esta Ley que introduce en nuestro Derecho el criterio de responsabilidad objetiva de la Administración pública presenta un carácter de normación horizontal aplicable a todas las esferas de la Administración pública, aunque ciertamente la del Estado va a presentar alguna peculiaridad en esta materia como consecuencia de la posterior Ley de Régimen Jurídico de la Admi-

${ }^{37}$ S. Muñoz Machado, La responsabilidad civil concurrente de las Administraciones públicas, Ed. Civitas, Madrid, 1992. 
nistración del Estado de $1957^{38}$. Justamente es esto lo que he señalado al comienzo de este trabajo, pero estos datos son bien conocidos por la doctrina y casi todos los operadores jurídicos.

Ahora estamos ya en condiciones de entrar en el estudio de la resolución objeto de este comentario jurisprudencial aunque debe tenerse en cuenta que los hechos se produjeron en el marco de la anterior normativa, razón por la cual, algunas conclusiones y afirmaciones de la sentencia comentada pueden parecer chocantes al lector y, desde luego - con eso y todo-, puede discreparse en algunos extremos de la misma y todo ello sin olvidar lo que yo mismo dije en su momento sobre esta cuestión con motivo del comentario de la sentencia de instancia posteriormente recurrida ente el Tribunal Supremo ${ }^{39}$.

\section{LA STS DE 15 DE JULIO DE 1998}

Es llegado el momento de analizar la STS de 15 de julio de 1998, Ar. 20814 - con independencia de lo que se dirá seguidamente en la Adden$d a$ que recoge este estudio jurisprudencial—, y que, en realidad, obedece al compromiso que adquirí con los lectores de la revista hace ya algunos años y que, por unas u otras razones, no he podido satisfacer hasta el momento ${ }^{40}$. Esta sentencia declara no haber lugar al recurso interpuesto por el Ayuntamiento de Galera (Granada) ${ }^{41}$, estimando en parte el recurso

38 J. L. Martínez-López MuÑiz, La responsabilidad patrimonial de los poderes públicos, Ed. Marcial Pons, Madrid, 1999, pp. 508 y ss.

39 F. J. JimÉNEZ LeChUGA, «Responsabilidad patrimonial de las Administraciones públicas. Indemnidad patrimonial de los perjudicados y equilibrio económico-financiero de las Corporaciones locales (el caso de la sentencia del TSJA, Sala de lo Contencioso-Administrativo de Granada, Sección primera, de 6 de febrero de 1995)», Revista de Estudios Locales (CUNAL), n. ${ }^{\circ} 10,1996$.

40 F. J. JimÉnez LeChUGA, «Responsabilidad patrimonial de las Administraciones públicas...», obra cit., nota n. $^{\circ} 39$.

${ }^{41}$ Por cierto que, como no podría ser de otro modo si hemos de hacer honor a la verdad, en 1996 solicité la colaboración de la Corporación afectada sin que existiese inconveniente alguno en aquel momento. Lamentablemente, no puede decirse lo mismo esta vez. En efecto, mediante escrito de 23 de agosto de 2001 - reiterando su contenido por otro de 19 de septiembre siguiente-, se solicitó fotocopia de las resoluciones judiciales ahora comentadas y de los demás datos que, obrantes en el expediente que debía poseer el Ayuntamiento demandado, se juzgasen convenientes para la mejor información de los lectores de este segundo trabajo mío sobre la cuestión. Esto se reiteró al alcalde y secretario de aquel Ayuntamiento en varias ocasiones pero, hasta la fecha de cierre de este estudio y envío a la imprenta — día 8 de octubre de 2001—, no se ha recibido respuesta alguna. Como entiendo que esta colaboración era obligada, la pasividad del alcalde es, cuando menos, censurable. A veces piensa uno, cuando visita pueblos de España, que detrás del sustantivo Ayuntamiento no existe nada, aunque para el Derecho positivo estamos en presencia de Administraciones públicas de base territorial. Y lo peor es que esta callada por respuesta existe también en los grandes Ayunta- 
contencioso-administrativo ${ }^{42}$ formulado por los actores contra acuerdo de la citada Corporación en materia de responsabilidad patrimonial. Se estima en concreto la alegación de incongruencia omisiva del artículo 359 LEC, pues tiene razón el recurrente cuando dice que la sentencia afirmó que éste no impugnó las cantidades reclamadas, cuando tal impugnación se había producido. Por tanto, entrando en el fondo del asunto, relativo al quantum de la pretensión indemnizatoria de los actores, del examen de la prueba documental existente en autos resulta la estimación de una de las valoraciones, por ser la única que da razón de ciencia de la valoración que refiere a valores de mercado.

Los hechos, en síntesis, fueron los siguientes. La Sentencia del TSJA (Sala de lo Contencioso-Administrativo de Granada), de 6 de febrero de $1995^{43}$ condenaba al Ayuntamiento de Galera (Granada) al pago de determinadas cantidades en concepto de indemnización por los daños sufridos como consecuencia de las filtraciones de la red del abastecimiento en las viviendas de los afectados en determinadas cantidades al haber quedado las casas-cueva hundidas por este evento. El 21 de marzo de 1995 se preparó el recurso de casación ante el Tribunal Supremo y los recurrentes (no todos) se opusieron a tal pretensión de la Administración municipal demandada, presentándose después el recurso y contestado por los vecinos (varios) y continuando la tramitación conforme a la Ley Rituaria ${ }^{44}$.

Seguidamente razona la Sala que es cierto que la falta de motivación del Tribunal a quo (la Sala de Granada) puede constituir un supuesto de incongruencia omisiva, habiéndolo así establecido el Tribunal Constitucional en Sentencia 5/1986, por cuanto este tipo de incongruencia tiene su motivación en el deber de motivar las sentencias proclamado en el artículo $24 \mathrm{CE}$, de tal manera que la congruencia no se establece solamente entre las pretensiones y la resolución, sino entre aquéllas y la motivación de ésta, de modo que deben ser examinadas todas las cuestiones que integran el fundamento de lo demandado y la oposición, afirmando que parece claro que la sentencia de instancia debía analizar esta cuestión valorando las pruebas aportadas por una y otra parte y al no hacerlo así, limitán-

mientos. Desde aquí, pues, quede constancia de la descortesía del alcalde de Galera (Granada) y ello por no ser más vehemente en mis afirmaciones.

${ }^{42}$ Sentencia del TSJA (Sala de lo Contencioso-Administrativo de Granada, Sección primera) dimanante del recurso del mismo nombre interpuesto por varios vecinos de Galera (Granada) (Rec. n. $\left.{ }^{\circ} 2411 / 1992\right)$ y que yo mismo comenté en el número 10/1996 de la Revista de Estudios Locales (CUNAL), pp. 61 y ss.

${ }^{43}$ La sentencia comentada en la Revista de Estudios Locales (CUNAL) n. ${ }^{\circ} 10,1996$.

44 Téngase en cuenta lo que después se dice en la Addenda. 
dose a afirmar que no habían sido impugnadas las cantidades reclamadas por los actores en concepto de indemnización, es claro que dejó de examinar una de las cuestiones que integran la causa petendi de la oposición a la pretensión de los actores y, en consecuencia, incurrió en el vicio de incongruencia invocado por el recurrente en casación, lo que necesariamente lleva a la estimación del motivo articulado.

Rechaza el segundo motivo del recurso - basado éste en la violación del art. 632 LEC-, al entender la Sala que los informes obrantes en el expediente, al no haberse practicado prueba pericial durante el proceso, aquéllos tienen tal carácter siendo lo actuando conforme con el artículo 610 del mismo cuerpo legal.

Es el tercer motivo de casación con mucho el más interesante a los efectos que ahora ocupan. Sostiene el Tribunal Supremo que este motivo de casación articulado por infracción del artículo 54 de la Ley 7/1985, de 2 de abril, debe decaer, al ser doctrina de la Sala que la responsabilidad recae sobre quien es titular del servicio cuyo anormal funcionamiento origina el daño, ya que es este titular quien viene obligado a realizar las actuaciones necesarias en orden al mantenimiento de las instalaciones que garanticen el buen funcionamiento de aquél, con independencia y sin perjuicio de que pueda repetir contra terceros si se dan los requisitos necesarios para ello. En el caso de autos el daño viene producido por una fuga en la red de abastecimiento del servicio municipal de aguas $y$, por tanto, el responsable es el Ayuntamiento demandado por más que la obra de infraestructura haya sido ejecutada con cargo a los presupuestos de los Planes de Obras y Servicios de la Diputación, nada tiene que ver la financiación con la titularidad del servicio y de los medios utilizados para la prestación del mismo, titularidad que en ningún momento se discute sea municipal. El Ayuntamiento demandado es quien, en consecuencia, venía obligado a velar por el buen funcionamiento y mantenimiento de las instalaciones y de las instalaciones que constituyen su soporte material y al no hacerlo su actuar es relevante en cuanto al resultado producido, sin que pueda hablarse de ruptura del nexo causal en base a un hipotético defecto de las instalaciones motivado por una anomalía de construcción, que de acreditarse únicamente daría lugar a la posibilidad de repetir frente al responsable si se cumplen los restantes requisitos, entre ellos los temporales para el ejercicio de la acción correspondiente.

Hasta aquí los razonamientos de la Sala son irreprochables. En lo que se refiere al nexo causal, es evidente que éste existió y que si las viviendas (cuevas) se hundieron, lo fue como consecuencia de los recalamien- 
tos por las mismas padecidos y provenientes de un terreno arcilloso en el que transcurrían las conducciones de aguas potables del anejo de la Alquería. También parece incuestionable que el titular del servicio lo era y es el Ayuntamiento ahora condenado, obligado, por tanto, a su cuidado y mantenimiento. Además, y para colmo de males, es cierto que no fueron las lluvias torrenciales del 7 de septiembre de 1989 las que ocasionaron tal hundimiento y me atrevo a creer que incluso ni a ello contribuyeron en nada. Ahora bien, desde la promulgación de la Ley 30/1992, de 26 de noviembre (modificada por la Ley 4/1999, de 13 de enero, art. 140), parece evidente que el principio de la solidaridad aplicado al instituto sería perfectamente posible cabiendo, por ejemplo, demandar sólo a Diputación provincial y, condenada ésta, podría repetir contra el Ayuntamiento respectivo. A ello contribuye la nueva regulación así como al espíritu garantista que preside la institución desde 1954. Luego, sería menester constatar en qué medida la realización de las obras ha sido defectuosa, pero esto no puede afectar a los perjudicados. También conviene tener presente que estos Ayuntamientos carecen de medios técnicos incluso para el mantenimiento de las instalaciones (servicio de aguas potables, saneamientos, escuelas de enseñanza primaria) pero tampoco debe esto perjudicar a los lesionados. La solución propuesta podría salvar muchos casos en que, como en el de autos, se ha tardado años en solucionar el problema (más de una década).

En cuanto al cuarto motivo de la casación, mantiene el TS que procede entrar a examinar la cuestión en los términos que ha quedado planteada y así, establecida como está la realidad del daño y la existencia del nexo causal entre éste y el funcionamiento del servicio público municipal ${ }^{45}$ de abastecimiento de aguas, la única cuestión a resolver es el «quantum indemnizatorio» para lo que se hace preciso examinar la prueba documental existente en autos integrada por los informes técnicos aportados por las partes con tal carácter, debiendo rechazarse, por falta absoluta de motivación, el suscrito por doña Belén, de la Unidad de Asistencia Técnica Municipal de la Diputación de Granada, amén de que la técnico informante afirma que no ha podido determinar las características y la superficie de las viviendas afectadas, concluyendo que, en relación con las valoraciones efectuadas por los Arquitectos Sres. M. y O., no tiene en cuenta el hecho de que en la tasación debe excluirse la valoración del suelo, debiendo tenerse en cuenta en los demás extremos, como efectivamente se hace.

45 A. Nieto García, «La relación de causalidad en la responsabilidad del Estado», REDA, n. ${ }^{\circ} 4$, 1975. 
Concluye la sentencia con el fallo según el cual se estima en lo expuesto el recurso de casación contra la sentencia también referida pero confirma la apelada condenando al Ayuntamiento de Galera a indemnizar a don Marcelino, don Sebastián, don Ángel y don Antonio en las cantidades de 6.916.000, 3.925.000, 6.075.000 y 5.010.000 ptas., respectivamente, devengando los intereses legales desde el 9 de octubre de 1992 incrementado en dos puntos porcentuales.

Hasta aquí el contenido de la sentencia objeto de mi comentario en esta revista.

\section{CONCLUSIONES}

En vista de todo lo anterior, parece evidente que, al quedar constitucionalizado el instituto resarcitorio, no se ha introducido una novedad relevante, pero sí se convierte en una guía para el legislador ordinario aunque, como se ha dicho, la libertad en la concepción del sistema de responsabilidad administrativa en nuestro Derecho es muy amplia y algunos sostienen que puede llegarse incluso a un sistema corregido a la baja e incluso de carácter subjetivo o culpabilístico. Ésta no es mi interpretación del artículo 106.2 CE ni creo que sea tampoco la del Tribunal Constitucional aunque en alguna sentencia parezca haber aludido a esta posibilidad. En resumen:

Primero. El sistema español de responsabilidad administrativa es el más avanzado de los países de nuestro entorno y su carácter de autónomo, directo y objetivo, no deben desaparecer del esquema del artículo 139 y ss. de la Ley 30/1992, de 26 de noviembre. Si acaso, la falla puede encontrarse en la falta de desarrollo de la responsabilidad por las Leyes en que incurra el Estado, problema éste que, según me parece, aunque en esto me encuentro en franca minoría, no está resuelto ${ }^{46}$.

\footnotetext{
${ }^{46}$ M. ${ }^{a}$ C. Alonso García, La responsabilidad patrimonial del Estado legislador, Ed. Marcial Pons, Madrid, 1999. Por cierto que, según he comprobado, se están elaborando algunos trabajos de posgrado sobre estas cuestiones y algún alumno mío esta preparando su trabajo sobre estos temas, pero desde el punto de vista de un tributarista, hay que denunciar otra vez desde aquí algunos de los males que aquejan a la Universidad española (masificación, falta de medios e instalaciones y falta de formación del profesorado, endogamia académica, inadecuación de los planes de estudio, etc.). Estos males han sido denunciados tempranamente por Amando DE Miguel, Alejandro Nieto García y Lorenzo MARTín-Retortillo BAQUer. Este último - por lo que se refiere ahora a la vocación universitaria de los alumnos- escribía hace sólo unos años que éstos, a la hora de comenzar sus estudios, deberían preguntarse si servirían para ello, si les gustaba lo que iban a estudiar y si estaban dispuestos a arrostrar el esfuerzo o sacrificio que su decisión positiva comportaría. Resulta evidente, sin embargo, que la incuria y la penuria en que se mueve la Universidad española son lamentables. Da pena ver tanto mediocre en la Universidad («eruditos a la violeta» como expresiva-
} 
Segundo. No parece dudoso que el nexo causal se ha dado en el caso de la sentencia estudiada así como los demás requisitos necesarios para la declaración de responsabilidad a la Administración municipal demandada.

Tercero. Por lo demás, y en lo atinente a la responsabilidad solidaria de las Administraciones públicas, resulta de todo punto patente y meridiano que el leit motiv de la nueva regulación no es otro que la salvaguarda de la garantía patrimonial de las personas lesionadas. Por tanto, en adelante, si se ha producido un daño individual y económicamente evaluable en cuya causación hayan intervenido varios Entes públicos, como resultado de fórmulas de gestión convenidas de servicios públicos, podrá el particular, desde un punto de vista procesal, dirigirse contra cualquiera de los entes intervinientes sin perjuicio de las acciones de repetición o regreso que asistan al condenado a indemnizar a la víctima del daño. Aquí sigue existiendo la duda de si es posible el litisconsorcio pasivo necesario, siendo uno de los codemandados un particular, aunque habría que decantarse por la solución positiva ya que, en otro caso, el archiconocido «peregrinaje de jurisdicciones» seguirá existiendo. En esto no ha sido clara ni acertada la Ley 29/1998, de 13 de junio, al no haberlo establecido expresamente.

Tampoco me parece feliz la falta de regulación del litisconsorcio activo por la nueva Ley rituaria. Ello comporta algunos problemas que se han planteado ya en la práctica cuando llevamos sólo tres años de vigencia de la nueva ley (Ley 29/1998, de julio). Me refiero al hecho procesal paradójico de que, por ejemplo, entablada una demanda (interpuesto un recurso contencioso-administrativo) contra una resolución administrativa, estuviesen varios interesados en desacuerdo, razón por la que se entabla la demanda. Supongamos también que, presentada la demanda y transcurridas ciertas fases procesales, algún otro interesado conoce la existencia del proceso, habiendo participado previamente en el procedimiento y siendo interesado en el mismo (porque se lo comunica a la Administración demandada), y quiere, puesto que el plazo para interponer el recurso proba-

mente dice A. NiETo GARCíA). Resulta penoso, en contrapartida, contemplar cómo muchos jóvenes de valía tienen que replegarse ante los confaloneros del catedrático de turno y derivar hacia la Administración, mientras que un montón de inútiles se perpetúan en las Facultades de Derecho (como becarios, pero también como catedráticos y titulares). No sé si la nueva Ley de Universidades con la implantación de la habilitación nacional arreglará algo. Por de pronto, mi opinión es más bien negativa, no sólo porque el sistema putrefacto y hediondo se va a perpetuar, al ser los jueces los mismos, sino por la simple similitud de la denominación del título habilitante con el de los secretarios de Ayuntamiento. Puede ser que los nuevos concursos de traslados eliminarían en algo el «localismo» pero la duda sólo se despejará cuando hayan pasado varias años si es que la ley llega a ser aprobada (proyecto de ley). 
blemente ya habrá transcurrido con creces, adherirse a la primera demanda interpuesta. Es seguro que el Juzgado rechaza tal pretensión por extemporánea al entender que no está regulada en la referida Ley esta figura procesal adhitiva. Es evidente, por fin, que de lege ferenda la situación debe cambiar a condición de tener en cuenta, como ocurre en el procedimiento administrativo, que la personación del codemandante (tardía) habrá de tenerse por válida, sin perjuicio de la preclusión ya producida.

Cuarto. En cuanto a la responsabilidad patrimonial del Estado legislador - aunque no es el objeto de este comentario jurisprudencial- sí cabe afirmar que el artículo $9 \mathrm{CE}$ está necesitado de una regulación y que, mientras ésta sea la que es ex artículo 139.3 LRJ y PAC, no cabe hablar de esta responsabilidad más que cuando la Ley así lo establezca individualmente en cada caso o que el legislador negativo (TC) la declarase expresamente ${ }^{47}$. En otro caso, es decir, mientras este precepto constitucional no se sea desarrollado, sigo alineado en esto con J. LEGUINA VILLA como ya he indicado más atrás ${ }^{48}$.

Éste será el caballo de batalla de la doctrina en los próximos años, aparte de otras consignas apocalípticas que pueden leerse por doquier dentro de la literatura jurídica y que no son sino meras alucinaciones o desvaríos de quienes las propagan pero que son irrazonables.

\section{ADDENDA}

A punto de cerrar este trabajo y remitir el original a la imprenta, aunque tardíamente, he descubierto la existencia de otra sentencia del TSJA (la misma Sala de Granada), en la que se recoge igual problemática ${ }^{49}$ que la aquí tratada. Se trata de la Sentencia de 29 de enero de 1996, dimanante del recurso contencioso-administrativo n. ${ }^{\circ} 1491 / 1993$ y la dictada en casación por el Tribunal Supremo, de 13 de octubre de 1998, Ar. 27802. En esta última, se alegan como motivos de casación el artículo 95.1.3..$^{\circ}$ de la vieja LEC (es decir, LJCA) por infracción a su vez del artículo 359 LEC, al entender que no tenía la sentencia casada la claridad y precisión suficientes, sobre todo en lo que se refiere a la valoración de los daños oca-

\footnotetext{
${ }^{47}$ M. ${ }^{\text {a }}$ C. Alonso García, La responsabilidad patrimonial del Estado legislador, Ed. Marcial Pons, Madrid, 1999.

48 J. Leguina Villa y M. Sánchez Morón, La nueva Ley de Régimen Jurídico de las Administraciones Públicas y del Procedimiento Administrativo Común, Ed. Tecnos, Madrid, 1993.

${ }^{49}$ Se trata, como es natural, de una falta de colaboración del alcalde de Galera (Granada) como ya he indicado antes.
} 
sionados, habiéndose empleado, en su momento también, a la Diputación de Granada y el empresario así como al Director de las referidas obras. Es interesante la afirmación de la aludida sentencia del TS cuando dice que, ciertamente, no se contiene en la sentencia ninguna referencia expresa a la aludida posible responsabilidad de la Diputación Provincial de Granada y del Director y ejecutor de la instalación, en su día, de la instalación del servicio de aguas de Galera como debió de haberse efectuado, pero tal omisión no es constitutiva de la causa de incongruencia alegada entre las pretensiones ejercitadas y la resolución combatida porque, como ya se ha referido, en la sentencia se reconoce de modo taxativo la responsabilidad patrimonial del Ayuntamiento de Galera, debido al mal funcionamiento del servicio municipal de aguas de este ente local, por lo que tan rotunda imputación de responsabilidad patrimonial al Ayuntamiento aquí recurrente, implica de modo consecuente la inexistencia de responsabilidad patrimonial de la Diputación granadina, o del ingeniero director o del empresario ejecutor de la obra ${ }^{50}$.

El segundo motivo de casación alegado - y que el TS desestima íntegramente - es la presunta infracción del artículo 54 de la Ley 7/1985, de 2 de abril, reguladora de les Bases de Régimen Local, porque - dice el TS invocando la STS de 15 de julio de 1998, ya comentada - los daños en las viviendas de los afectados ha sido producido, por una fuga en la red del servicio de abastecimiento municipal de aguas y, por ende, el responsable es el Ayuntamiento demandado en la instancia, aunque la obra de instalación de las tuberías de conducción del agua hubiese sido ejecutada en su día con cargo a los Planes de Obras y Servicios de la Diputación, pues ello nada tiene que ver con la titularidad del servicio y de los medios utilizados para la prestación del mismo, titularidad inexcusablemente municipal. Termina desestimando el recurso interpuesto ${ }^{51}$.

\footnotetext{
50 Ya ha quedado indicado que quizás hoy la solución sería distinta a la luz del artículo 140 de la Ley 30/1992, de 26 de noviembre, de Régimen Jurídico de las Administraciones Públicas y del Procedimiento Administrativo Común.

${ }^{51}$ E. García de EnterRía, Jueces y seguridad jurídica en un mundo de leyes desbocadas, Ed. Civitas, Madrid, 1999. Seguramente, coherente con mi concepción de la Administración local — casi de las demás cosas de la vida cabria decir-, y desde el punto de vista del irracionalismo sociológico al que se refiere F. SAinz Moreno en uno de sus libros, cabría decir que el Ayuntamiento condenado pensó que por lo que más se nos castiga es por nuestras virtudes y, precisamente, una de las más destacadas en los Ayuntamientos españoles es su inactividad casi permanente y endémica. Seguramente también este pensamiento podría ser un aforismo de F. NiETSCHE si se bucea en sus obras puesto que yo de la lectura de ellas lo recuerdo.
} 
